\title{
Characterization of Mechanical Heterogeneity in Dissimilar Metal Welded Joints
}

\author{
He Xue ${ }^{1, * \mathbb{C}}$, Zheng Wang ${ }^{1} \mathbb{D}$, Shuai Wang ${ }^{1} \mathbb{D}$, Jinxuan $\mathrm{He}^{1}$ and Hongliang Yang ${ }^{2}$ \\ 1 School of Mechanical Engineering, Xi'an University of Science and Technology, Xi'an 710054, China; \\ 19205201083@stu.xust.edu.cn (Z.W.); 17101016005@stu.xust.edu.cn (S.W.); hjx84118631@163.com (J.H.) \\ 2 Center of Engineering Training, Xi'an University of Science and Technology, Xi'an 710054, China; \\ hl_yang@163.com \\ * Correspondence: xuehe@xust.edu.cn
}

check for updates

Citation: Xue, H.; Wang, Z.; Wang, S.; He, J.; Yang, H. Characterization of Mechanical Heterogeneity in Dissimilar Metal Welded Joints. Materials 2021, 14, 4145. https:// doi.org/10.3390/ma14154145

Academic Editors: Bin Wang and Arash Soleiman-Fallah

Received: 17 June 2021

Accepted: 22 July 2021

Published: 26 July 2021

Publisher's Note: MDPI stays neutral with regard to jurisdictional claims in published maps and institutional affiliations.

Copyright: (c) 2021 by the authors. Licensee MDPI, Basel, Switzerland. This article is an open access article distributed under the terms and conditions of the Creative Commons Attribution (CC BY) license (https:// creativecommons.org/licenses/by/ $4.0 /)$.

\begin{abstract}
Dissimilar metal welded joints (DMWJs) possess significant localized mechanical heterogeneity. Using finite element software ABAQUS with the User-defined Material (UMAT) subroutine, this study proposed a constitutive equation that may be used to express the heterogeneous mechanical properties of the heat-affected and fusion zones at the interfaces in DMWJs. By eliminating sudden stress changes at the material interfaces, the proposed approach provides a more realistic and accurate characterization of the mechanical heterogeneity in the local regions of DMWJs than existing methods. As such, the proposed approach enables the structural integrity of DMWJs to be analyzed in greater detail.
\end{abstract}

Keywords: dissimilar metal welded joints; mechanical heterogeneity; UMAT; numerical simulations; integrity assessment

\section{Introduction}

The leading pressure-bearing equipment in the primary water systems of pressurized water reactors (PWRs) is connected to the main pipeline using a safe-end dissimilar metal welded joint (DMWJ). Because of their high corrosion resistance and suitable mechanical properties, nickel-based alloys are widely used as welding metals for connecting stainless steel piping and pressure vessel nozzles [1,2]. In general, DMWJs consist of at least three base materials and weld materials and are subjected to a variety of complex loads while in service; therefore, structural failures often occur at DMWJs [1-3]. Given their status as a critical region for structural integrity analysis, the mechanical heterogeneity in the locality of DMWJs needs to be expressed appropriately. However, current approaches for assessing the structural integrity of DMWJs have certain limitations and rely heavily on the use of general material strength analysis and the operational experience of the inspector [4]. As such, a more accurate expression of the mechanical heterogeneity of DMWJs is required to assist in the analysis of their local mechanical properties [5].

The highly heterogeneous distribution of fracture properties, mechanical properties, and microstructure along the DMWJ has restricted the development of mechanical property evaluation systems [6,7]. Existing structural integrity assessments of welded joints, such as those proposed by Fan et al. [8,9] and Xue et al. [10], tend to ignore the influence of the heat-affected zone (HAZ) and the fusion zone (FZ). The simple bi- or tri-material models typically used do not evaluate the mechanical properties of strength-mismatched welded joints directly, potentially affecting the accuracy of calculations. Engineering applications that consider the mechanical heterogeneity of DMWJs usually use sandwich composite structures [11-13]. For simplicity, the welded joints are partitioned, with each partition corresponding to the mechanical parameters of a specific material. Despite their outstanding structural properties, such sandwich composite structures are mismatched in terms of their interregional material and geometric properties $[14,15]$. Significant interfacial stress 
variations, induced by mechanical loadings, occur at each regional interface [16,17]. Consequently, sandwich composite structures retain several limitations in terms of expressing the mechanical properties of the materials in the locality of the DMWJ $[18,19]$. To address the abrupt changes in the interfacial stresses encountered in simplified sandwich composite structures, a temperature field can be introduced to analyze the mechanical behavior in the locality of the DMWJ. To approximate the mechanical heterogeneity in terms of the temperature field, different temperatures can be defined at different locations [20,21]. By reproducing this method, we found that it yielded an approximation of the mechanical heterogeneity in the local regions of the DMWJ. To represent the mechanical heterogeneity at arbitrary positions in a simple and robust manner, the mechanical parameters were defined for the different element integration points [22].

This objectives of this study were: (i) to develop a more appropriate method for characterizing the mechanical heterogeneity of the DMWJ based on the User- defined Materials (UMAT) subroutine and (ii) to elucidate the variation of mechanical properties in the local regions of the DMWJ. The heat-affected and fusion zones of mechanical heterogeneity were considered in the analysis of the changes in the mechanical behavior of local regions of the DMWJ. Numerical simulations of the stress-strain curves at different positions in the vicinity of the DMWJ interface indicated that the interface location was likely to be a weak point in DMWJ failure. The proposed method can be applied to analyze the integrity of important engineering structures and to improve the stability of vulnerable structures.

\section{Materials and Methods}

\subsection{UMAT Theoretical Basis}

The UMAT subroutine in the finite element analysis (FEA) software ABAQUS (Abaqus 6.14, Dassault Systemes, Paris, France) can be used to define the mechanical behavior of materials and perform calculations at different element integration points [23]. In this study, the mechanical behavior of the element integration points was matched, pointby-point, to the coordinate positions in order to determine the mechanical properties at different positions in the DMWJ more realistically. Compared with previous methods, this approach was simpler and offered better accuracy and reproducibility. The UMAT subroutine calculated the trial and equivalent stresses, the equivalent plastic strain, and updated the state variables.

When an external force is applied, the subroutine calculates the elastic trial stress $\sigma_{n+1}^{\text {trial }}$ at the moment $(n+1)$ based on the total strain increment $\Delta \varepsilon$ applied at the moment $t_{n}$; thus, the total strain increment $\Delta \varepsilon$ is decomposed as

$$
\Delta \varepsilon=\Delta \varepsilon_{e}+\Delta \varepsilon_{p}
$$

where $\Delta \varepsilon_{e}$ and $\Delta \varepsilon_{p}$ are the elastic and plastic components of the total strain, respectively.

Based on the assumption that the initial state is purely elastic, the trial stress at the beginning of the subroutine can be expressed as

$$
\sigma_{n+1}^{\text {trial }}=\sigma_{n}+D_{e}: \Delta \varepsilon_{e}
$$

where trial represents the trial state and $D_{e}$ is the Jacobian matrix in the elastic state:

$$
D_{e}=\frac{E}{2(1+v)}\left(\delta_{i k} \delta_{j l}+\delta_{i l} \delta_{j k}\right)+\frac{v E}{(1+v)(1-2 v)}\left(\delta_{i j} \delta_{k l}\right),
$$

where $\delta_{i j}$ denotes the abbreviation for the unit matrix (when $i=j, \delta_{i j}=1$; when $i \neq j$, $\left.\delta_{i j}=0\right), E$ is Young's modulus, and $v$ is Poisson's ratio.

Next, the equivalent stress $\bar{\sigma}$ can be expressed as [24]

$$
\bar{\sigma}=\sqrt{\frac{3}{2}}\|S\|,
$$


where $S$ represents deviatoric stress.

According to the $J_{2}$ flow rule [22],

$$
\Delta \varepsilon_{p}=\Delta \lambda \frac{3 S}{2 \bar{\sigma}}
$$

which means that the plastic strain $\varepsilon_{n+1}^{p}$ at the moment $t_{n+1}$ is

$$
\varepsilon_{n+1}^{p}=\varepsilon_{n}^{p}+1.5 \Delta \lambda \frac{s_{n+1}^{\text {trial }}}{\bar{\sigma}_{n+1}^{\text {trial }}} .
$$

According to Ref. [24], the equivalent plastic strain increment at the $n$th step is

$$
\Delta \varepsilon_{n}^{p}=\Delta \lambda=\frac{f_{n+1}^{\text {trial }}}{H+3 G} .
$$

Updating the stress values in the UMAT subroutine necessitates using different algorithms for the elastic and plastic stages. When the stress lies within the elastic range, the relationship between the stress and strain increments can be expressed as

$$
d \sigma=D_{e}\left(d \varepsilon-d \varepsilon_{p}\right)
$$

whereas when the stress is beyond the elastic range

$$
d \sigma=D_{e p} d \varepsilon,
$$

where $D_{e p}=D_{e}-D_{p}$ in which $D_{p}=\frac{9 G^{2} * S * S^{T}}{\bar{\sigma}^{2}\left(H^{\prime}+3 G\right)}[24,25]$.

The integration algorithm used by the UMAT subroutine comprises two main parts: the elastic trial and the return mapping. When loaded by an external force, the elastic trial stress $\sigma_{n+1}^{\text {trial }}$ at the moment $t_{n+1}$ and the difference between it and the yield function $f_{n+1}^{\text {trial }}$ are calculated by the subroutine according to the total strain increment $\Delta \varepsilon$ applied at the moment $t_{n}$, with the outcome determining whether the stress enters the plastic phase. When $f_{n+1}^{\text {trial }} \leq 0$, the integration algorithm is in the elastic phase (a). In addition, because the plastic strain increment $\Delta \lambda=0$, the total strain increment $\Delta \varepsilon$ represents the elastic strain increment and the elastic stiffness matrix $D_{e}$ is used to update the stress at time $t_{n}$ to that at time $t_{n+1}$. Conversely, when $f_{n+1}^{\text {trial }}>0$, the integration algorithm is in the plastic phase (b); therefore, the plastic strain increment $\Delta \lambda>0$, the total strain increment $\Delta \varepsilon$ is decomposed into elastic strain increment $\Delta \varepsilon_{e}$ and plastic strain increment $\Delta \varepsilon_{p}$, and the stress entering the plastic stage uses the elastic-plastic stiffness matrix $D_{e p}$ to update the stress at time $t_{n}$ to that at time $t_{n+1}$. Figure 1 shows the corresponding algorithm flow diagram.

\subsection{Material Model}

The DMWJs were modelled using Alloy52M as the filler metal and low-alloy steel (LAS) SA508 and austenitic stainless steel 316L as the base metal [26]. The chemical compositions of various materials are listed in Table 1 [26]. The DMWJ sample is shown in Figure 2. The weld metal consisted of buttering Alloy52Mb $(52 \mathrm{Mb})$ and weld Alloy52Mw $(52 \mathrm{Mw})$. The inner wall of the tube possessed an overlayer of austenitic stainless steel 304. This study focused mainly on the base metal (SA508 and 316L) and weld (Alloy52M) zones, where the mechanical heterogeneity was clearest.

Table 2 lists the room-temperature mechanical properties of various DMWJ materials according to Refs. [20,27]. 


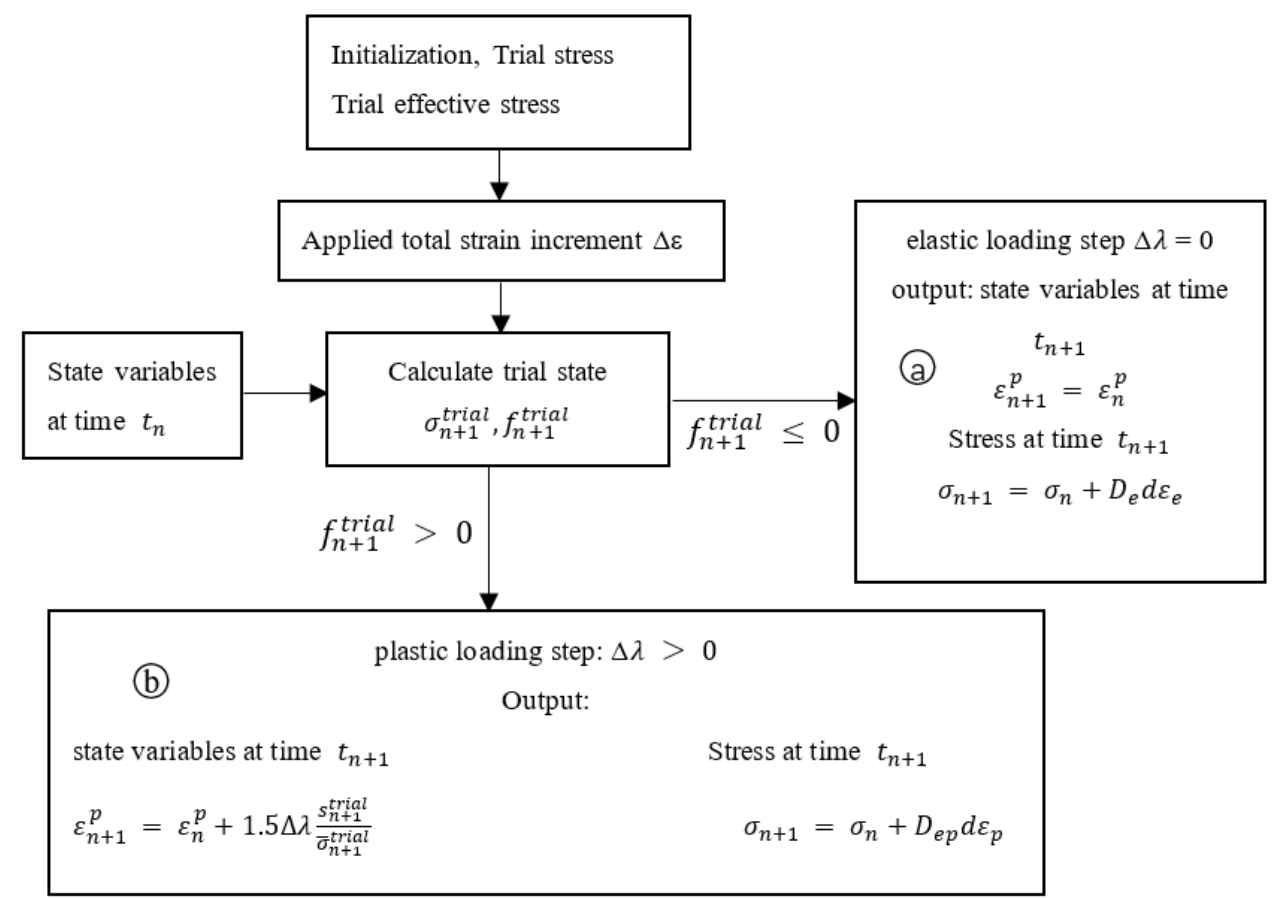

Figure 1. Schematic diagram of subroutine flow.

Table 1. Chemical composition of materials used in dissimilar metal weld joints (DMWJs) [26].

\begin{tabular}{lcccccccccc}
\hline Material & $\mathbf{C}$ & $\mathbf{S i}$ & $\mathbf{M n}$ & $\mathbf{C r}$ & $\mathbf{S}$ & $\mathbf{N i}$ & $\mathbf{F e}$ & $\mathbf{P}$ & $\mathbf{M o}$ & $\mathbf{N}$ \\
\hline SA508 & 0.170 & 0.210 & 1.360 & 0.16 & 0.001 & 0.80 & Bal. & 0.006 & 0.490 & - \\
52Mb & 0.020 & 0.110 & 0.890 & 29.77 & $<0.0005$ & 59.20 & 8.73 & 0.003 & 0.008 & 0.006 \\
52Mw & 0.023 & 0.110 & 0.900 & 29.77 & $<0.0005$ & 59.30 & 8.74 & 0.003 & 0.100 & 0.006 \\
316L & 0.014 & 0.624 & 1.576 & 17.34 & $<0.001$ & 10.84 & Bal. & 0.026 & 2.210 & 0.116 \\
\hline
\end{tabular}

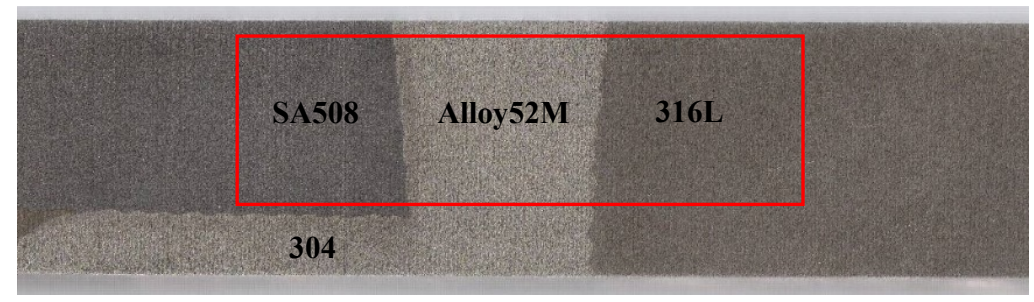

Figure 2. Physical diagram of dissimilar metal welded joints and sampling area.

Table 2. Mechanical properties of various DMWJ materials at room temperature [20,27].

\begin{tabular}{ccccc}
\hline Materials & $\begin{array}{c}\text { Young's } \\
\text { Modulus } \\
\boldsymbol{E}, \mathbf{M P a}\end{array}$ & $\begin{array}{c}\text { Poisson's Ratio } \\
\boldsymbol{v}\end{array}$ & $\begin{array}{c}\text { Yield Strength } \\
\sigma_{\boldsymbol{y}}, \mathbf{M P a}\end{array}$ & $\begin{array}{c}\text { Hardening } \\
\text { Coefficient } \\
\boldsymbol{H}^{\prime}\end{array}$ \\
\hline SA508 & 202,410 & 0.3 & 426 & 1100 \\
Alloy52M & 178,130 & 0.3 & 400 & 1000 \\
316L & 202,000 & 0.3 & 345 & 850 \\
\hline
\end{tabular}

When $\sigma \leq \sigma_{y}$, the material deforms elastically, whereas when $\sigma>\sigma_{y}$, the material deforms plastically; thus

$$
\sigma=\left\{\begin{array}{cl}
E \varepsilon_{e}, & \sigma \leq \sigma_{y} \\
\sigma_{y}+H^{\prime}\left(\varepsilon_{P}\right), & \sigma>\sigma_{y}
\end{array},\right.
$$

where $\sigma$ is the stress, $\varepsilon_{e}$ is the elastic strain, $\sigma_{y}$ is the yield strength of the material, and $H^{\prime}$ is the material hardening coefficient in the plastic deformation phase. 
The continuous transition model developed in this study considers the continuous variation of the mechanical properties of the materials along the DMWJ. Taking the axial direction as the $y$-direction, the yield strength $\sigma_{y}$ of the welded joint varies along the axial direction according to the function $\sigma_{y}(y)$; upon entering the plastic deformation stage, the hardening coefficient $H^{\prime}$ changes according to the function $H^{\prime}(y)$. The yield strength $\sigma_{y}$ at different positions and the plastic-phase hardening coefficient $H^{\prime}$ are expressed as

$$
\left\{\begin{array}{c}
\sigma_{y}=\sigma_{y}(y) \\
H^{\prime}=H^{\prime}(y)
\end{array} .\right.
$$

Substituting Equation (11) into Equation (10) yields the principal equation for the continuous variation of the mechanical properties along the DMWJ:

$$
\sigma=\left\{\begin{array}{cl}
E \varepsilon_{e}, & \sigma \leq \sigma_{y} \\
\sigma_{y}(y)+H^{\prime}(y)\left(\varepsilon_{P}\right), & \sigma>\sigma_{y}
\end{array} .\right.
$$

In the UMAT subroutine, the mechanical heterogeneity of the DMWJ is characterized by defining $E, v, \sigma_{y}(y)$, and $H^{\prime}(y)$. at different positions in the DMWJ to establish a finite element model and then analyzing it.

Following the approach described in [28], the relationships between hardness and the yield and ultimate strengths in the base metal, HAZ, and weld metal are described by Equation (13). In addition, Equation (14) describes the plastic-phase hardening coefficient:

$$
\left\{\begin{array}{cc}
\sigma_{y}=3.28 H V-221 & (\mathrm{BM}, \mathrm{HAZ}) \\
\sigma_{u}=3.29 H V-47 & (\mathrm{BM}, \mathrm{HAZ}) \\
\sigma_{y}=3.15 H V-168 & (\mathrm{WM}) \\
\sigma_{u}=2.84 H V+28 & (\mathrm{WM})
\end{array},\right.
$$

According to References. $[3,11,27]$, the yield strengths of the DMWJ constituent materials (SA508, Alloy52M, and 316L) at room temperature were determined to be $426 \mathrm{MPa}$, $400 \mathrm{MPa}$, and $345 \mathrm{MPa}$, respectively. However, the local mechanical properties of the HAZ and the FZ during welding differed substantially from those of the base material (BM) and the weld metal (WM). Therefore, for the interface region, considering only the mechanical properties of the BM or WM may produce nonconservative (unsafe) or overly conservative results. By applying the empirical conversion equation to microhardness experimental data [28], the yield strength and hardening coefficient distributions at different positions along the DMWJ can be obtained, as shown in Figure 3.

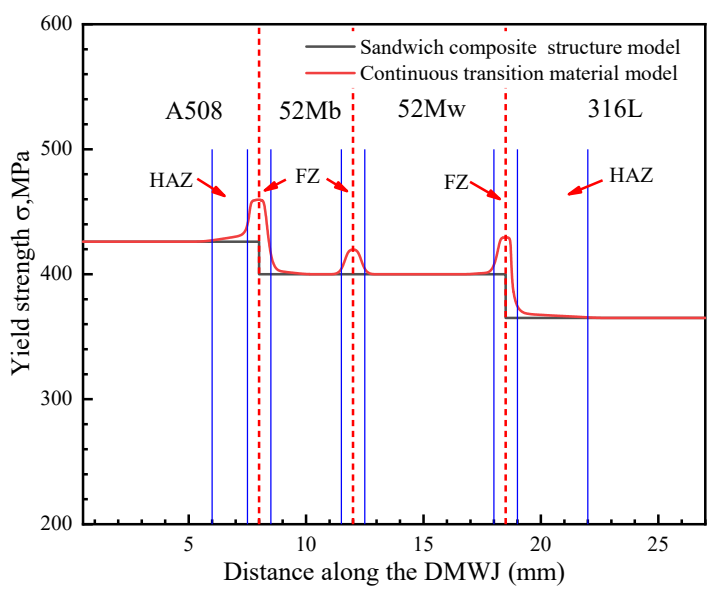

(a)

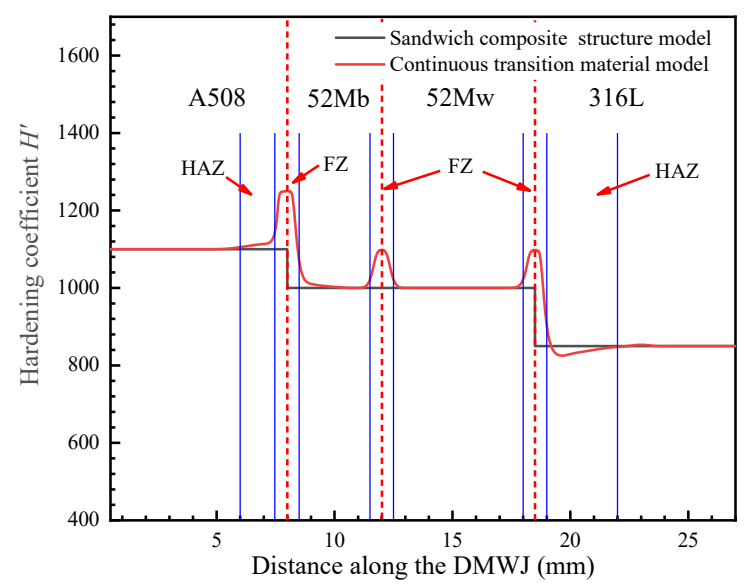

(b)

Figure 3. Distributions of (a) yield strength and (b) hardening coefficient along the DMWJ. 
Combined with the yield strength and hardening coefficient distributions along the DMWJ, this study used a polynomial function with a curve fitting correlation coefficient of $R^{2} \geq 0.95$ to fit the individual regions of the yield strength and hardening coefficient distributions obtained using the continuous transition material model. The continuous changes in the mechanical properties of the materials in the DMWJ interface region were considered in the constitutive equation and integrated into the UMAT subroutine:

$$
\begin{gathered}
\sigma_{y}=\left\{\begin{array}{lr}
426 & y \in[0,6.0] \\
429.7-3.5 y+0.5 y^{2} & y \in(6.0,7.5] \\
-11,077+2913 y-184 y^{2} & y \in(7.5,8.5] \\
400 & y \in(8.5,11.5] \\
-12,414+2139 y-89.1 y^{2} & y \in(11.5,12.5] \\
400 & y \in(12.5,18.0] \\
-61,463+6724.5 y-182.65 y^{2} & y \in(18.0,19.0] \\
365 & y \in(19.0,27.0]
\end{array}\right. \\
H=\left\{\begin{array}{lr}
1100 & y \in[0,6.0] \\
884.1+60.8 y-4 y^{2} & y \in(6.0,7.5] \\
-49,186+12,719 y-801.3 y^{2} & y \in(7.5,8.5] \\
1000 & y \in(8.5,11.5] \\
-63,069.14+10,697 y-445.7 y^{2} & y \in(11.5,12.5] \\
1000 & y \in(12.5,18.0] \\
-249,904.163+27,253.1 y-739.7 y^{2} & y \in(18.0,19.0] \\
74,094.72-10,621.2 y+512.34 y^{2}-8.22 y^{3} & y \in(19.0,23.0] \\
850 & y \in(23.0,27.0]
\end{array}\right.
\end{gathered}
$$

For analyses using the sandwich structure, the model was partitioned, with different regions assigned different yield strengths as per Equation (17):

$$
\sigma_{y}=\left\{\begin{array}{rr}
426 & y \in[0,8.0] \\
400 & y \in[8.0,18.5] \\
365 & y \in[18.5,27.0]
\end{array}\right.
$$

\subsection{Geometric Model}

The DMWJ consisted of a base metal (A508 and 316L) away from the interface and a weld metal (buttering Alloy52Mb and weld Alloy52Mw). The transition from the base metal to the weld zone inevitably caused lattice distortion. Therefore, a narrow (0.5-1 $\mathrm{mm}$ ) fusion zone (FZ) occurred near the interface-the composition, microstructure, and hardness of which all changed significantly. In addition, the structure and properties of the HAZ (1-5 mm) were unevenly distributed, owing to the heat-related effects of welding $[3,11,17]$. Figure 4 shows a simplified schematic diagram of the structure used for the FEA. It is important to note that material interfaces will not be perfectly straight in reality; however, for simplicity, straight interfaces were used in all simulations.

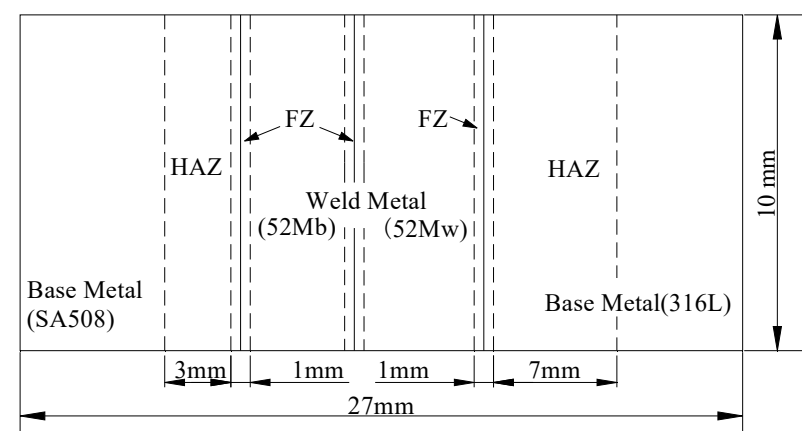

Figure 4. Schematic diagram of each region in the simplified welded structure. 


\subsection{Mesh and Load Model}

Although welding is a three-dimensional process, it is widely acknowledged that axisymmetric models are appropriate for simulating the welding of cylindrical structures to determine the local mechanical properties of DMWJs [29]. Therefore, axisymmetric finite element models, which are fast and easy to use, are widely used to simulate heterogeneity. As shown in Figure 5, the mesh was composed of 4-node bilinear axisymmetric elements (CAX4) with a total of 1080 elements $(0.5 \mathrm{~mm} \times 0.5 \mathrm{~mm})$. Displacement and rotation constraints were applied to the left end of the model in the $y$-direction and around the $x$-direction, respectively. The mechanical properties of the model were compared and analyzed by applying $U_{y}=0.5 \mathrm{~mm}$, pressure $=0 \mathrm{MPa}$, and $U_{y}=0.5 \mathrm{~mm}$, pressure $=100 \mathrm{MPa}$, respectively.

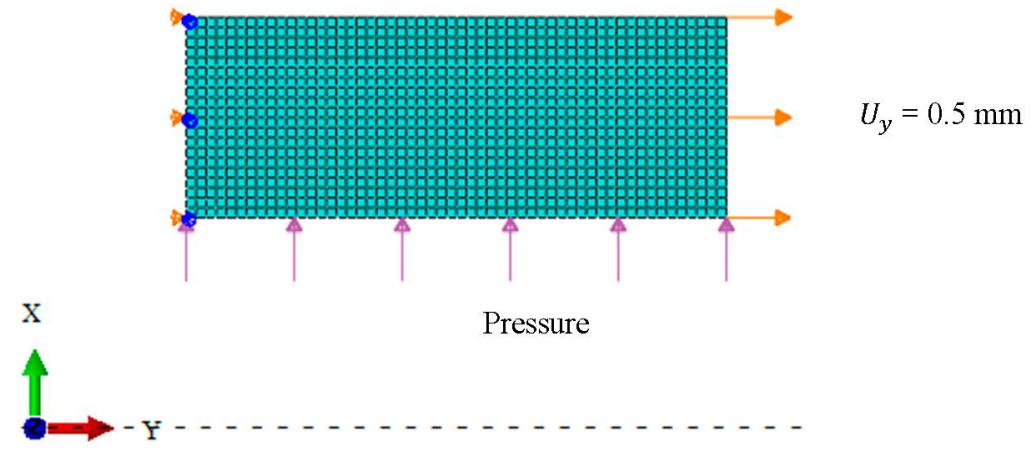

Figure 5. Finite element model of dissimilar metal welded joints.

\section{Results and Discussion}

\subsection{Continuous Transition Model Simulation Results}

The numerical simulation results for the model subjected to axial loading are shown in Figure 6. Specifically, Figure 6a,b show the stress results for the developed continuous transition and sandwich models, respectively. The results obtained for applying the continuous transition model revealed that the stress in the interface region gradually increased at first before gradually decreasing. In contrast, for the sandwich composite structure model, the stress at the interface changed suddenly. As shown in Figure 7, the models were subjected to axial loading and internal pressure simultaneously. As a consequence, the internal stresses of the model changed, although they remained most significant at the interface region. This highlights the importance of the interface region when assessing the structural integrity of DMWJs. The next section discusses the stressstrain relationship in the interface region for a representative example in which an axial loading of $0.5 \mathrm{~mm}$ was applied.

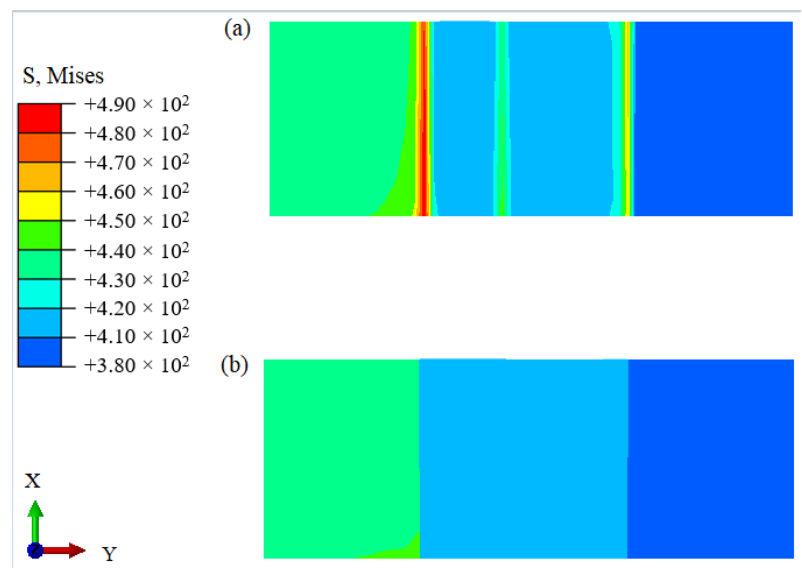

Figure 6. Numerical simulation results under an axial load: (a) continuous transition model, (b) sandwich model. 

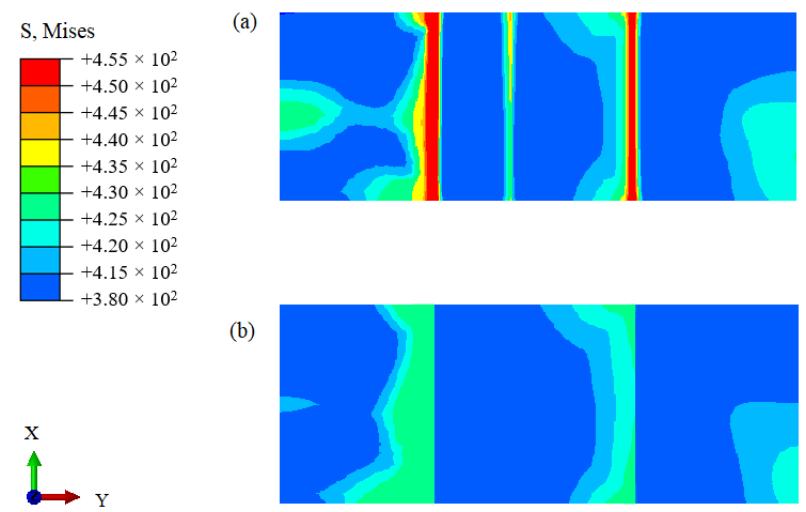

(b)

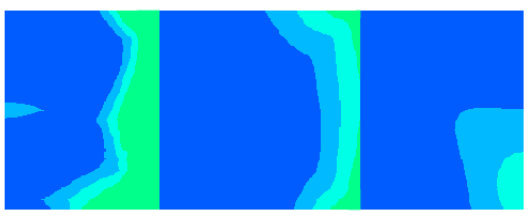

Figure 7. Numerical simulation results under the simultaneous action of axial load and internal pressure: (a) continuous transition model, (b) sandwich model.

\subsection{Local Stress-Strain Simulation Results at the SA508/52Mb and 52Mw/316L Interfaces}

Figure 8 a shows the stress-strain curves in the vicinity of the SA508/52Mb interface in response to an axial loading of $0.5 \mathrm{~mm}$. The curves indicate the presence of high stress and low strain in the HAZ of the SA508 material. In contrast, the $52 \mathrm{Mb}$ region exhibited low stress and high strain. Figure $8 \mathrm{~b}$ shows the stress-strain curves in the vicinity of the $52 \mathrm{Mw} / 316 \mathrm{~L}$ interface: compared with the 52Mw region, the $316 \mathrm{~L}$ region, which was situated farther from the interface, exhibited lower stress and higher plastic strain. Nevertheless, both interface regions showed high stress and plastic strain, which promotes crack initiation and growth. Therefore, from the numerical simulation results, we inferred that the interface represents a high-probability zone for DMWJ failure, which is consistent with experimental results reported in the literature [27,30]. Figure 8 shows that the maximum stress at position e in the SA508/52Mb interface zone was $485 \mathrm{MPa}$, while the stress at point a in the base material was $435 \mathrm{MPa}$, representing a difference of $50 \mathrm{MPa}$. The maximum stress at position $\mathrm{d}$ in the $52 \mathrm{Mb} / 316 \mathrm{~L}$ interface region was $450 \mathrm{MPa}$, while the maximum stress at point a in the $52 \mathrm{Mw}$ region was $415 \mathrm{MPa}$, representing a stress change of $35 \mathrm{MPa}$. Owing to the larger magnitude of the stress change in the SA508/52Mb interface region, it was deemed more susceptible to destruction. As such, it should be focused on.

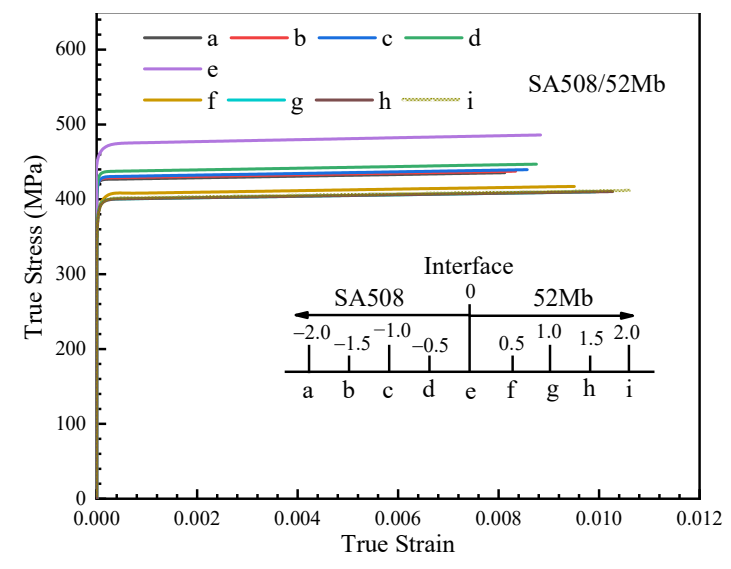

(a)

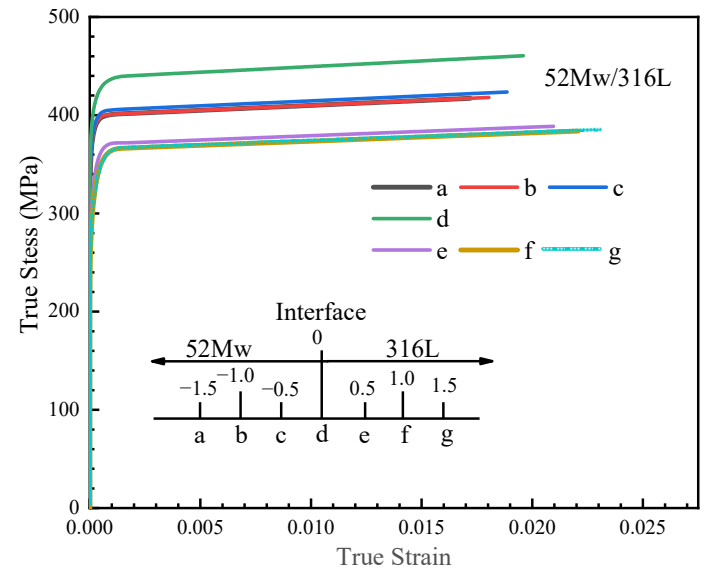

(b)

Figure 8. Stress-strain curves at the (a) SA508/52Mb and (b) 52Mw/316L interface zones.

\subsection{Effect of Mechanical Heterogeneity on the DMWJ Local Region Mechanical Properties}

From Figure 9, it can be seen that the stress component in the $x$-direction was compressed in both the sandwich structure model and in the continuous transition model-a phenomenon most likely due to the axial loading-induced displacement. Moreover, this 
phenomenon was amplified by the effects of internal pressure. It was evident that the stress in the interface region changed significantly.

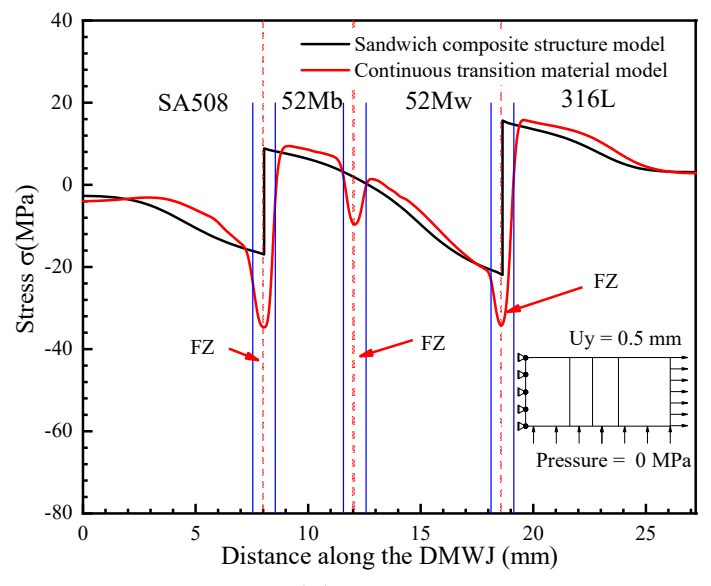

(a)

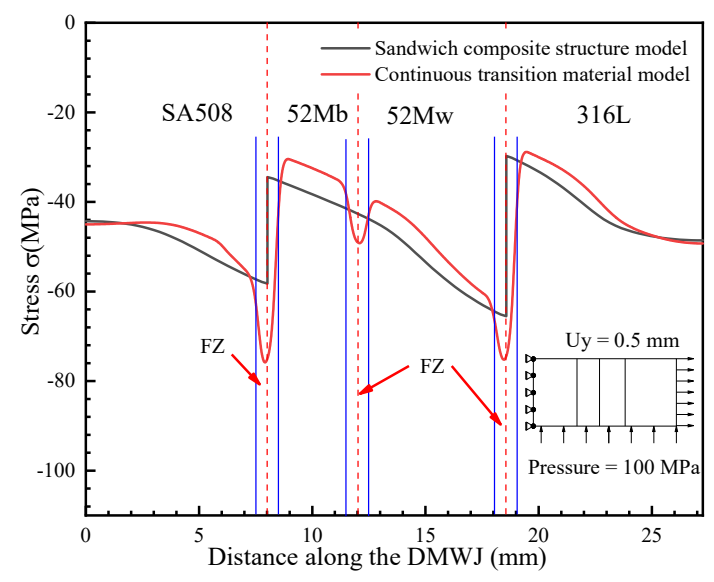

(b)

Figure 9. $X$-directional stress under (a) an axial load and (b) an axial load and internal pipe pressure.

As shown in Figure 10, when axial loads alone were considered, the $y$-directional stress component was significantly larger than when both the axial and the internal pipe pressure loads were considered. This is due to the reduction of the $y$-directional stress component by the internal pressure. The $y$-directional component exhibited the same behavior under both loading conditions, with the stress in the interface region changing abruptly. This further supports the need to prioritize the mechanical properties of the interface region.

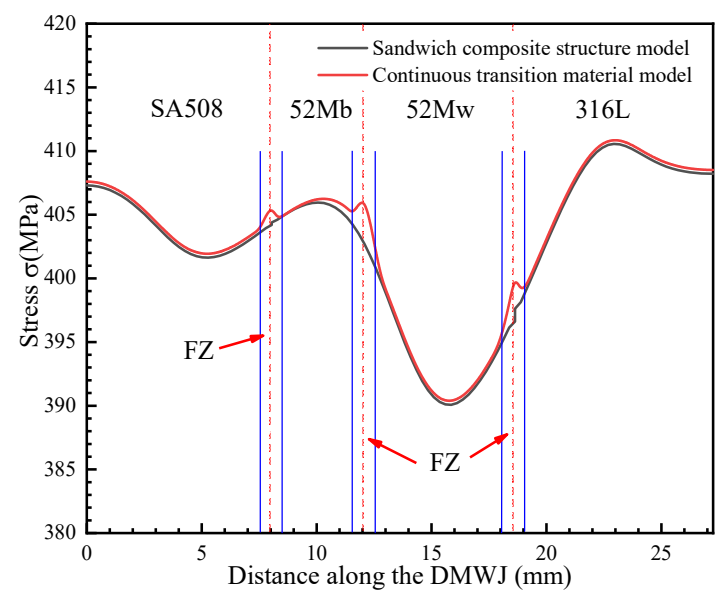

(a)

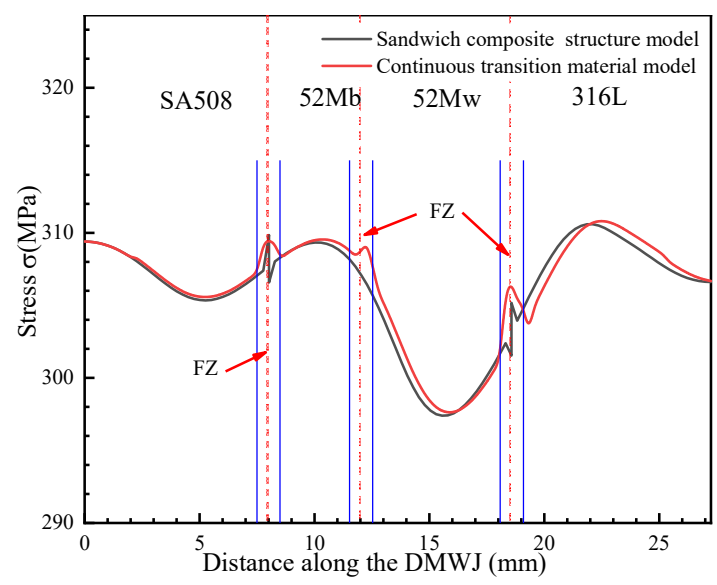

(b)

Figure 10. $Y$-directional stress under (a) an axial load and (b) an axial load and internal pipe pressure.

As shown in Figure 11, under an axial load, the sandwich structure model showed a significant increase in stress at the SA508/52M and 52M/316L interfaces. For an internal pressure loading, the opposite trend was observed and a sudden change in stress occurred at the interface region. The continuous transition model eliminated abrupt changes in stress, allowing for a continuous transition in the mechanical properties of the materials in the interface regions.

As shown in Figures 12-15, by combining the analysis results for the stress components in the $x-, y$-, and $z$-directions, it was concluded that the sandwich structure model exhibited an abrupt change in stress and in the equivalent plastic strain (PEEQ) in the interface region. This can be attributed to the fact that the model assigns different mechanical properties for different partitions, while ignoring the existence of the HAZ and FZ. As shown in 
Figure 12, the results upon applying the developed continuous transition model revealed that, in the SA508/52M interface region, the stress gradually increased to $485 \mathrm{MPa}$ before gradually decreasing to $405 \mathrm{MPa}$, whereas in the 52Mw/316L interface region, the stress gradually increased to $450 \mathrm{MPa}$ before gradually decreasing to $376 \mathrm{MPa}$. In the sandwich structure model, the stress values did not transition continuously in the interface region but instead changed abruptly. This was evident in the sudden stress changes (from $430 \mathrm{MPa}$ to $404 \mathrm{MPa}$ in the SA508/52Mb interface region and from $404 \mathrm{MPa}$ to $377 \mathrm{MPa}$ in the $52 \mathrm{Mw} / 316 \mathrm{~L}$ interface region). For an internal pressure of $100 \mathrm{MPa}$, the analysis method was the same. In addition, the method proposed in this study can characterize the variation of mechanical properties between overlay layers composed of $52 \mathrm{Mb}$ and $52 \mathrm{Mw}$. Thus, the method proposed herein is more appropriate for expressing the mechanical properties in the interface region and better for assessing the structural integrity of DMWJs.

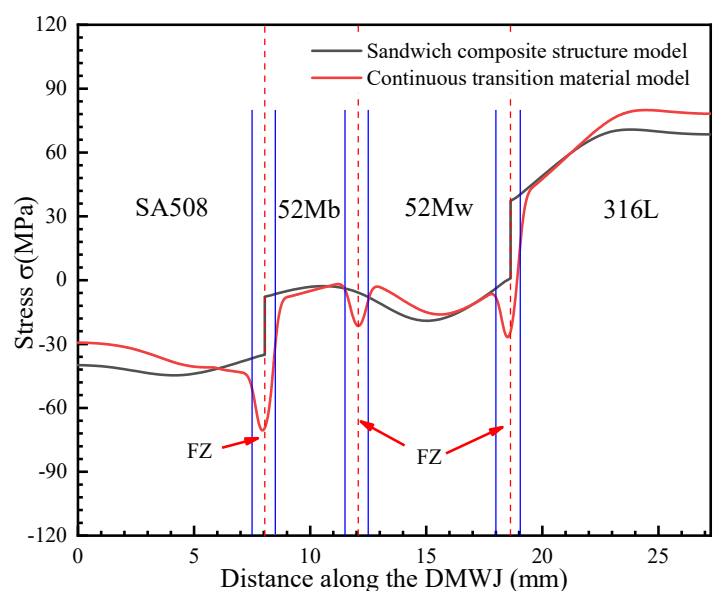

(a)

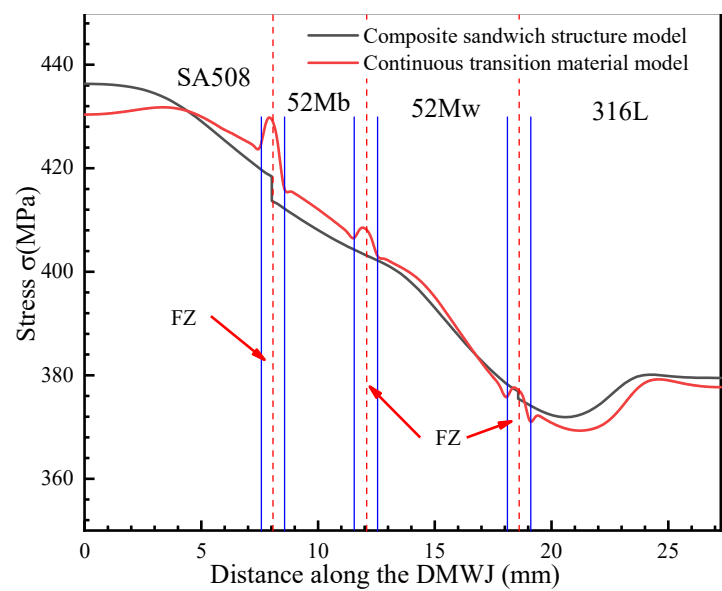

(b)

Figure 11. Z-direction stress under (a) an axial load and (b) an axial load and internal pipe pressure.

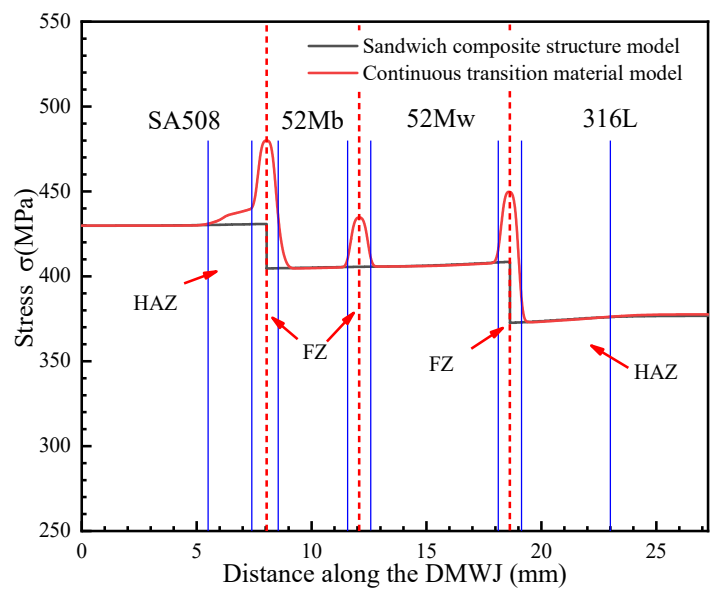

Figure 12. Stress along the DMWJ under an axial load.

The mechanical property variations shown in Figures 12-15 are in general agreement with the room temperature stress-strain results obtained for different regions of welded components in previous studies $[3,7,11]$. Sudden changes in stress in the interface regions caused subsequent changes in the PEEQ. Therefore, DMWJs possess significant mechanical heterogeneity in multi-material interface regions, and the use of conventional sandwich structure models to study DMWJs may produce nonconservative (unsafe) or overly conservative results. Consequently, the mechanical property distributions for DMWJ interface regions must be treated properly when assessing the structural integrity of DMWJs. 


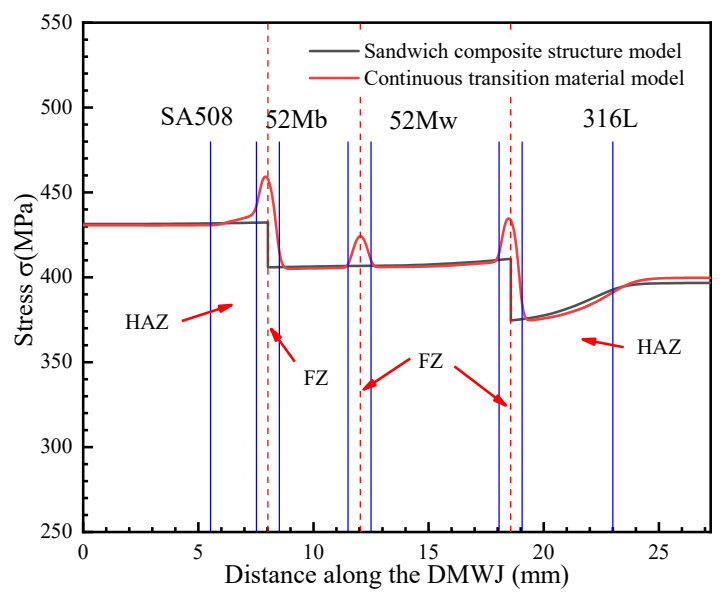

Figure 13. Stress along the DMWJ under an axial load and internal pipe pressure.

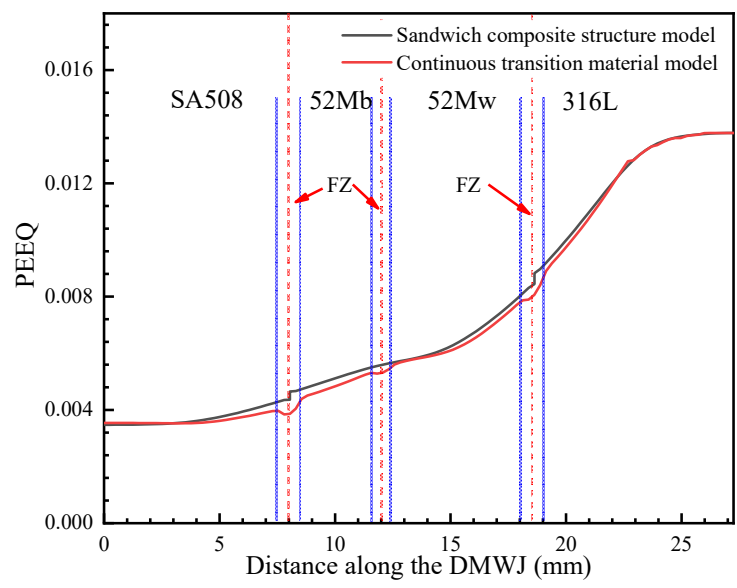

Figure 14. PEEQ along the DMWJ under an axial load.

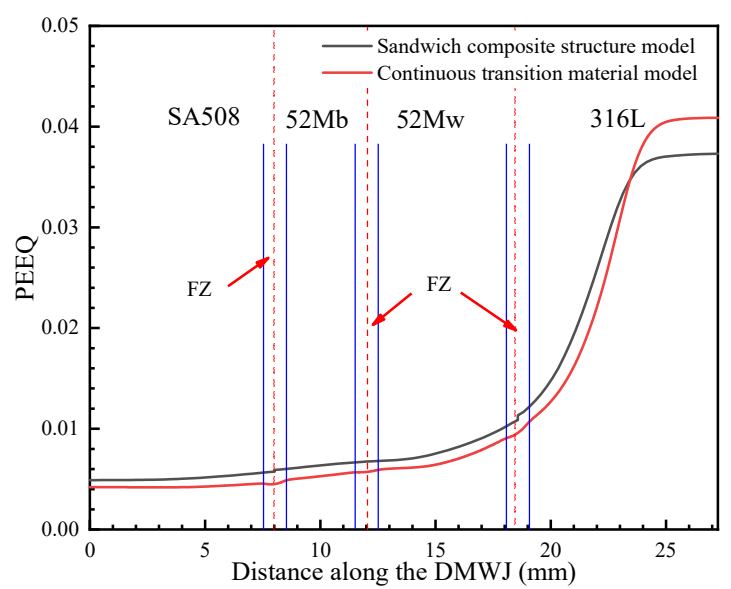

Figure 15. PEEQ along the DMWJ under an axial load and internal pipe pressure.

\section{Conclusions}

This paper presented an approach for characterizing the mechanical heterogeneity in the local regions of DMWJs. Variations of mechanical properties in the local regions of the DMWJ composed of Alloy52M were analyzed, leading to the following conclusions:

(1) The use of a user-defined material utility, UMAT, enables the continuous variation of mechanical properties in all regions of the DMWJ to be characterized to obtain more accurate and realistic results. 
(2) By considering the local mechanical heterogeneity, the proposed method avoids mismatching interregional material and geometric properties and eliminates abrupt changes in interfacial stresses. Accurate finite element simulations were performed using ABAQUS commercial software.

(3) Owing to their serious mechanical heterogeneities, particularly in the interface regions, the local mechanical properties of DMWJs change considerably. Compared with the $52 \mathrm{Mw} / 316 \mathrm{~L}$ interface region, the SA508/52Mb interface region is more susceptible to mechanical heterogeneity and should be regarded as a high-risk region in terms of structural integrity.

Finally, the proposed method can also be used to analyze the micromechanical fields and growth paths of cracks at different positions in mechanically heterogeneous DMWJ interface zones. Such analyses will be the subject of future research.

Author Contributions: Conceptualization, H.X.; data curation, J.H.; methodology, H.X.; software, Z.W.; validation, S.W.; visualization, H.Y.; writing—original draft, Z.W.; writing-review \& editing, Z.W. and H.Y.; formal analysis, J.H.; investigation, S.W. All authors have read and agreed to the published version of the manuscript.

Funding: This research was funded by National Natural Science Foundation of China (grant number 52075434). This research was also funded by Natural Science Foundation of Shaanxi Province (grant number 2021JM-389 and 2021KW-36). The APC was funded by 52075434.

Institutional Review Board Statement: Not applicable.

Informed Consent Statement: Not applicable.

Data Availability Statement: The data presented in this study are available on request from the corresponding author.

Conflicts of Interest: The authors declare no conflict of interest.

\section{References}

1. Andresen, P.L. A brief history of environmental cracking in hot water. Corrosion 2019, 75, 240-253. [CrossRef]

2. Chopra, O.K.; Chung, H.M.; Kassner, T.F.; Park, J.H.; Shack, W.J.; Zhang, J.; Brust, F.W.; Dong, P. Current research on environmentally assisted cracking in light water reactor environments. Nucl. Eng. Des. 1999, 194, 205-223. [CrossRef]

3. Ming, H.L.; Zhu, R.L.; Zhang, Z.M.; Wang, J.Q.; Han, E.H.; Ke, W.; Su, M.X. Microstructure local mechanical properties and stress corrosion cracking susceptibility of an SA508-52M-316LN safe-end dissimilar metal weld joint by GTAW. Mater. Sci. Eng. 2016, 669, 279-290. [CrossRef]

4. Chhibber, R.; Arora, N.; Gupta, S.R.; Dutta, B.K. Use of bimetallic welds in nuclear reactors: Associated problems and structural integrity assessment issues. Proc. Inst. Mech. Eng. Part C J. Mech. Eng. Sci. 2006, 220, 1121-1133. [CrossRef]

5. Lim, Y.S.; Kim, D.J.; Kim, S.W.; Kim, H.P. Crack growth and cracking behavior of Alloy 600/182 and Alloy 690/152 welds in simulated PWR primary water. Nucl. Eng.Technol. 2019, 51, 228-237. [CrossRef]

6. Dong, L.J.; Ma, C.; Peng, Q.J.; Han, E.H.; Ke, W. Microstructure and stress corrosion cracking of a SA508-309L/308L-316L dissimilar metal weld joint in primary pressurized water reactor environment. J. Mater. Sci. Technol. 2020, 40, 1-14. [CrossRef]

7. Wang, H.T.; Wang, G.Z.; Xuan, F.Z.; Liu, C.J.; Tu, S.T. Local mechanical properties of a dissimilar metal welded joint in nuclear power systems. Mater. Sci. Eng. 2013, 568, 108-117. [CrossRef]

8. Fan, K.; Wang, G.Z.; Tu, S.T.; Xuan, F.Z. Effects of toughness mismatch on failure behavior of Bi-material interfaces. Procedia Eng. 2015, 130, 754-762. [CrossRef]

9. Fan, K.; Wang, G.Z.; Xuan, F.Z.; Tu, S.T. Effects of work hardening mismatch on fracture resistance behavior of bi-material interface regions. Mater. Des. 2015, 68, 186-194. [CrossRef]

10. Xue, H.; Ogawa, K.; Shoji, T. Effect of welded mechanical heterogeneity on local stress and strain ahead of stationary and growing crack tips. Nucl. Eng. Des. 2008, 239, 628-640. [CrossRef]

11. Fan, K.; Wang, G.Z.; Yang, J.; Xuan, F.Z.; Tu, S.T. Numerical analysis of constraint and strength mismatch effects on local fracture resistance of bimetallic joints. Appl. Mech. Mater. Trans. Technol. 2015, 750, 24-31. [CrossRef]

12. Dong, L.; Peng, Q.; Han, E.-H.; Ke, W.; Wang, L. Microstructure and intergranular stress corrosion cracking susceptibility of a SA508-52M-316L dissimilar metal weld joint in primary water a dissimilar metal welded joint in nuclear power plants. Nucl. Eng. Des. 2013, 265, 145-153. [CrossRef]

13. Gan, J.L.; Peng, Y.; Dong, J. The Effect of the Heterogeneous Pattern of Material Mechanical Properties on the Structural Performance Analysis of Butt Joints. Prog. Steel Build. Struct. 2017, 19, 41-46. [CrossRef] 
14. Altenbach, H.; Altenbach, J.; Kissing, W. Mechanics of Composite Structural Elements, 2nd ed.; Springer: Singapore, 2018; pp. 503-504.

15. Burlayenko, V.N.; Sadowski, T.; Dimitrova, S. Three-dimensional free vibration analysis of thermally loaded FGM sandwich plates. Materials 2019, 12, 2377. [CrossRef]

16. Lu, C.; Zhao, M.; Jie, L.; Wang, J.; Gao, Y.; Cui, X.; Chen, P. Stress distribution on composite honeycomb sandwich structure suffered from bending load. Procedia Eng. 2015, 99, 405-412. [CrossRef]

17. Szekrényes, A. Analytical solution of some delamination scenarios in thick structural sandwich plates. J. Sandw. Struct. Mater. 2019, 21, 1271-1315. [CrossRef]

18. Geng, S.N.; Sun, J.S.; Guo, L.Y.; Wang, H.Q. Evolution of microstructure and corrosion behavior in 2205 duplex stainless steel GTA-welding joint. J. Manuf. Process. 2015, 19, 32-37. [CrossRef]

19. Xue, H.; Bi, Y.Q.; Wang, S.; Zhang, J.L.; Gou, S.Y. Compilation and Application of UMAT for Mechanical Properties of Heterogeneous Metal Welded Joints in Nuclear Power Materials. Adv. Mater. Sci. Eng. 2019. [CrossRef]

20. Guo, R.; Xue, H.; Gong, X.Y. Influence of residual stress and heterogeneity on mechanical field at crack tips in safety end of nuclear power plant. Procedia Struct. Integr. 2018, 13, 2202-2209. [CrossRef]

21. Zhao, L.Y.; Xue, H.; Jiao, K.; Tang, W. Stress Corrosion Cracking Behavior of an Alloy 182-A533B Weld Joint with Continuous Material Properties. Adv. Mater. Res. 2013, 716, 355-359. [CrossRef]

22. Lu, D.C.; Du, X.L.; Wang, G.S.; Zhou, A.N.; Li, A.K. A three-dimensional elastoplastic constitutive model for concrete. Comput. Struct. 2016, 163, 41-55. [CrossRef]

23. Yang, S.Y. Conversion of ABAQUS user material subroutines. J. Comput. Struct. Eng. Inst. Korea 2010, 23, 635-640.

24. Kim, J.; Kim, D.N. Robust stress integration algorithms for implicit elastoviscoplastic finite element analysis of materials with yield-point phenomenon. Int. J. Mech. Sci. 2019, 150, 277-289. [CrossRef]

25. Liao, D.; Yang, Z.X.; Xu, T.T. J2-deformation-type soil model coupled with state-dependent dilatancy and fabric evolution: Multiaxial formulation and FEM implementation. Comput. Geotech. 2021, 129, 103674. [CrossRef]

26. Ming, H.L.; Zhang, Z.M.; Wang, J.Q.; Han, E.H.; Su, M.X. Microstructure and local properties of a domestic safe-end dissimilar metal weld joint by using hot-wire GTAW. Acta Metall. Sin. 2016, 53, 57-69. [CrossRef]

27. Fan, K.; Wang, G.Z.; Xuan, F.Z.; Tu, S.T. Local fracture resistance behavior of interface regions in a dissimilar metal welded joint. Eng. Fract. Mech. 2015, 136, 279-291. [CrossRef]

28. Peng, Y.; Wu, C.; Gan, J.L.; Dong, J. Characterization of heterogeneous constitutive relationship of the welded joint based on the stress-hardness relationship using micro-hardness tests. Constr. Build. Mater. 2019, 202, 37-45. [CrossRef]

29. Liu, R.F.; Wang, J.C. Finite element analyses of the effect of weld overlay sizing on residual stresses of the dissimilar metal weld in PWRs. Nucl. Eng. Des. 2021, 372, 110959. [CrossRef]

30. Fan, K.; Wang, G.Z.; Xuan, F.Z.; Tu, S.T. Local failure behavior of a dissimilar metal interface region with mechanical heterogeneity. Eng. Fail. Anal. 2016, 59, 419-433. [CrossRef] 